\title{
High sampling rate thermistor string observations at the slope of Great Meteor Seamount
}

\author{
H. van Haren ${ }^{1}$, R. Groenewegen ${ }^{1}$, M. Laan ${ }^{1}$, and B. Koster ${ }^{1}$ \\ ${ }^{1}$ Royal Netherlands Institute for Sea Research (NIOZ), P.O. Box 59, 1790 AB Den Burg, The Netherlands
}

Received: 15 November 2004 - Published in Ocean Science Discussions: 22 December 2004

Revised: 7 March 2005 - Accepted: 30 March 2005 - Published: 10 May 2005

\begin{abstract}
A high sampling rate $(1 \mathrm{~Hz})$ thermistor string has been built to accommodate the scientific need to accurately monitor high-frequency and vigorous internal wave and overturning processes in the ocean. The thermistors and their custom designed electronics can register temperature at an estimated precision of about $0.001^{\circ} \mathrm{C}$ with a response time faster than $0.25 \mathrm{~s}$ down to depths of $6000 \mathrm{~m}$. With a quick in situ calibration using SBE 911 CTD an absolute accuracy of $0.005^{\circ} \mathrm{C}$ is obtained. The present string holds 128 sensors at $0.5 \mathrm{~m}$ intervals, which are all read-out within $0.5 \mathrm{~s}$. When sampling at $1 \mathrm{~Hz}$, the batteries and the memory capacity of the recorder allow for deployments of up to 2 weeks. In this paper, the instrument is described in some detail. Its performance is illustrated with examples from the first moored observations, which show Kelvin-Helmholtz overturning and very high-frequency (Doppler-shifted) internal waves besides occasionally large turbulent bores moving up the sloping side of Great Meteor Seamount, Canary Basin, North-Atlantic Ocean.
\end{abstract}

\section{Introduction}

After successful deployments of the first NIOZ thermistor string (NIOZ1: 32 sensors at $1 \mathrm{~m}$ intervals, sampled once per $20 \mathrm{~s}$, precision better than $4 \cdot 10^{-5^{\circ}} \mathrm{C}$; van Haren et al., 2001) plans were made to modify the concept, so that it would be better adapted for different environments. Specifically, we wanted to monitor over periods of a few weeks very fast $(\sim 1 \mathrm{~Hz})$ non-linear motions associated with internal "waves" in "solibore" form above sloping bottoms. Although such motions were captured with NIOZ1 (Hosegood et al., 2004), we wanted more detailed information, even more than presented by Thorpe (1987) who used an array of 11 thermis-

Correspondence to: H. van Haren

(hansvh@nioz.nl) tors at, on average, $10 \mathrm{~m}$ spacing, sampling every $10 \mathrm{~s}$ to a resolution of $10^{-4^{\circ}} \mathrm{C}$ at $\sim 3000 \mathrm{~m}$ depth off Porcupine Bank.

Except for Thorpe's deep-sea measurements (Thorpe, 1987) and in shallow water (Thorpe and Hall, 1974), very few "moored" observations have been made of highly varying temperatures as a measure for density $(\rho)$ variations. Such variations can occur as internal gravity waves that are supported by larger-scale stable density stratification, or as turbulence in mixing events. These processes are related because internal waves can generate turbulence when they break.

The frequency $(\sigma)$ of free propagating linear internal gravity waves is limited to $f<\sigma<N, N \gg f$. At the low end, $f=2 \Omega \sin \varphi$ denotes the local inertial frequency, the normal component of the Earth's angular momentum vector $\boldsymbol{\Omega}$ measured at latitude $\varphi$. At the high end, $N=(-g d \ln \rho / d z)^{1 / 2}$ the background buoyancy frequency, with $g$ the acceleration of gravity, pointing in the downward, negative z-direction. The vertical length scale of $N$ is crucial for the natural frequency of vertical oscillatory motion. However, motions at all scales cause density stratification changes (straining) of many different length and time scales (Pinkel et al., 1991). Thus, internal waves appear not just as linear waves, and, in the time domain, non-linear internal waves show steep ramps, i.e. sudden temperature changes within a period of less than 1 min only (Thorpe and Hall, 1974; Thorpe, 1987; Gemmrich and van Haren, 2001). Such steep waves may overturn when they propagate in larger-scale current shear thereby generating turbulent mixing through KelvinHelmholtz (shear) instability (Turner, 1973). In the open ocean typical vertical mixing scales are several meters, unstable overturning remaining for periods of several minutes $-1 \mathrm{~h}$, as determined using 3-4 min repeated CTD and microstructure profiles (Alford and Pinkel, 2000).

Even faster temperature variations of $\mathrm{O}(1 \mathrm{~s})$ having vertical scales of $\mathrm{O}(1 \mathrm{~m})$ have been observed in the upper $100 \mathrm{~m}$ of the ocean using "towed" thermistor string observations,

(C) 2005 Author(s). This work is licensed under a Creative Commons License. 
Table 1. Specifications of NIOZ thermistor strings. Compared to the very precise NIOZ1 the new NIOZ2 is somewhat less precise but it can sample many more sensors in a much shorter period of time.

\begin{tabular}{|c|c|c|}
\hline & NIOZ v.1 & NIOZ v.2 \\
\hline Number of sensors 32 & (at $1 \mathrm{~m}$ intervals) (*** $^{*}$ & 128 (at $0.5 \mathrm{~m}$ intervals) $* * *$ \\
\hline Depth rating & $6000 \mathrm{~m}$ & $6000 \mathrm{~m}$ \\
\hline Range (T) & $-5 \ldots . .55^{\circ} \mathrm{C}$ & $-2 \ldots . .50^{\circ} \mathrm{C}$ \\
\hline Precision & $<5 \cdot 10^{-4^{\circ}} \mathrm{C}$ & $1.5 \cdot 10^{-3^{\circ}} \mathrm{C}$ \\
\hline Thermistors* & 2 per sensor & 1 per sensor \\
\hline Self heating & $\cong 3 \cdot 10^{-4^{\circ}} \mathrm{C}$ & $\cong 1 \cdot 10^{-3^{\circ}} \mathrm{C}$ \\
\hline Response time $(\tau)$ & $<0.25 \mathrm{~s}$ (in water) & $<0.25 \mathrm{~s}$ (in water) \\
\hline Total sampling time & $<4$ s (for 32 sensors) & $0.5 \mathrm{~s}$ (for 128 sensors) \\
\hline Minimal sampling interval $(\Delta t)$ & $20 \mathrm{~s}$ & $1 \mathrm{~s}$ \\
\hline Memory and battery life & 100 days ( $\Delta t=30 \mathrm{~s} ; 32$ sensors $)$ & 15 days $(\Delta t=1 \mathrm{~s} ; 128 \text { sensors })^{* *}$ \\
\hline
\end{tabular}

* Siemens Matsushita B57017-K822.

** 512 MB Flash card installed. Sufficient power capacity to upgrade to 2 GB.

*** Maximum distance between sensors. Lines are flexible to make sensor distances smaller.

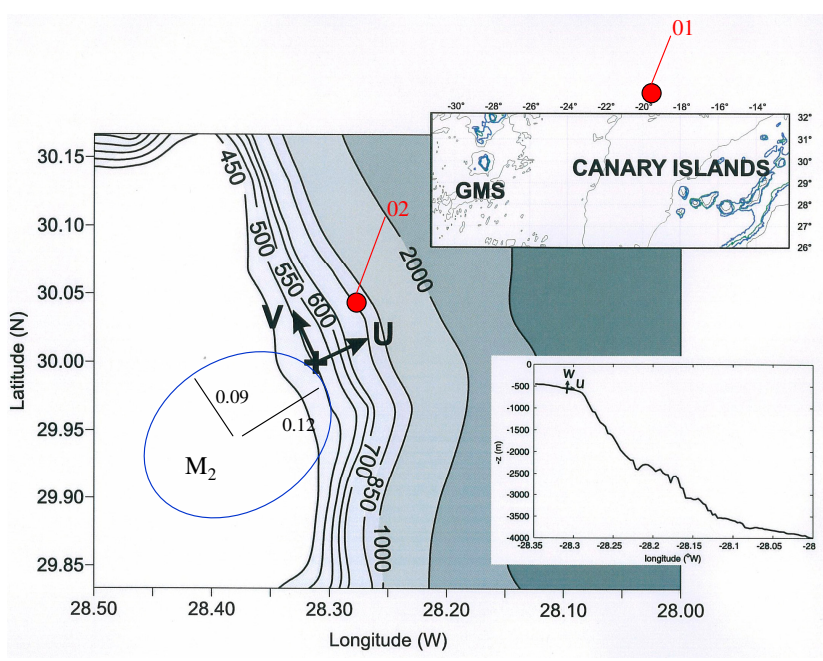

Fig. 1. Mooring site, positions of CTD01 and 02 and local coordinate axes at GMS. The $\mathrm{M}_{2}$ tidal ellipse (with major/minor axes in $\mathrm{m}$ $\mathrm{s}^{-1}$ ) is from observations by Mohn and Beckmann (2002). Amplitudes are about 1.5 times those from a numerical model they used and about 3.4 times the far field CB values in the same model.

whilst sampling at $0.1-4 \mathrm{~Hz}$ (e.g. Marmorino et al., 1987; Moum et al., 1992; Brandt et al., 1999). These thermistor strings had an accuracy of $\sim 10^{-2}{ }^{\circ} \mathrm{C}$ (Marmorino et al., 1987; Selschopp, 1997). As suggested from the "moored" observations by Thorpe (1987) and Hosegood et al. (2004), such temperature variations can be expected even in deepocean environments, despite the local background buoyancy period, which is relatively large $\mathrm{O}(10-100 \mathrm{~min})$.

As a result, for monitoring such deep internal temperature variations standard moored thermistor strings sample too slow, typically once per minute at an accuracy of $\sim 5 \cdot 10^{-2}{ }^{\circ} \mathrm{C}$. To monitor the above variations and scales at an accuracy better than $10^{-2}{ }^{\circ} \mathrm{C}$ one should modify a string of the towed type to one that can be moored. Alternatively, one could construct an (expensive) chain of individually logging temperature sensors, such as SBE39. These sensors are quite accurate $\left(2 \cdot 10^{-3^{\circ}} \mathrm{C}\right)$, but presently they cannot sample faster than once per $3 \mathrm{~s}$, whilst running out of power within 6 days when sampling at this rate. So far, a thermistor string has not been marketed that meets the above requirements.

Thus, new insights are expected from the newly built moored thermistor string "NIOZ2" that can resolve the finest non-linear internal wave fluctuations and scales of $\mathrm{O}(1 \mathrm{~m})$ and $\mathrm{O}(1 \mathrm{~s})$ over a range of $50-100 \mathrm{~m}$ sampling at a rate of $1 \mathrm{~Hz}$. This string also has the potential, with some limitation, to monitor the effects of overturning via eddy diffusivity $K$ estimates from "Thorpe overturning" scales $d$, which are found from re-ordering an unstable density profile to a stable one: $K=0.1 \mathrm{~d}^{2} / N$ (Thorpe, 1987). The limitation to estimate such $K$ using NIOZ2 is the present vertical sensor separation of $0.5 \mathrm{~m}$, which is somewhat large, where one would like to resolve $\mathrm{O}(0.01-0.1 \mathrm{~m})$ scales.

Following the principle of operation of NIOZ2, observations are presented from its first moored deployment near the top of Great Meteor Seamount (GMS) at latitude $\varphi=30.00^{\circ}$, at which $f$ equals the diurnal tidal frequency $K_{1}$ (Fig. 1). The sloping boundary layer of this site is expected to show interesting variations, because the dominant tidal currents have their major axis directed more or less perpendicular to the slope (Mohn and Beckmann, 2002). These tidal currents are described as mainy barotropic. The only substantial internal tidal wave motions at GMS have been found at the diurnal frequency $K_{1}$, but to the south of the present mooring. 


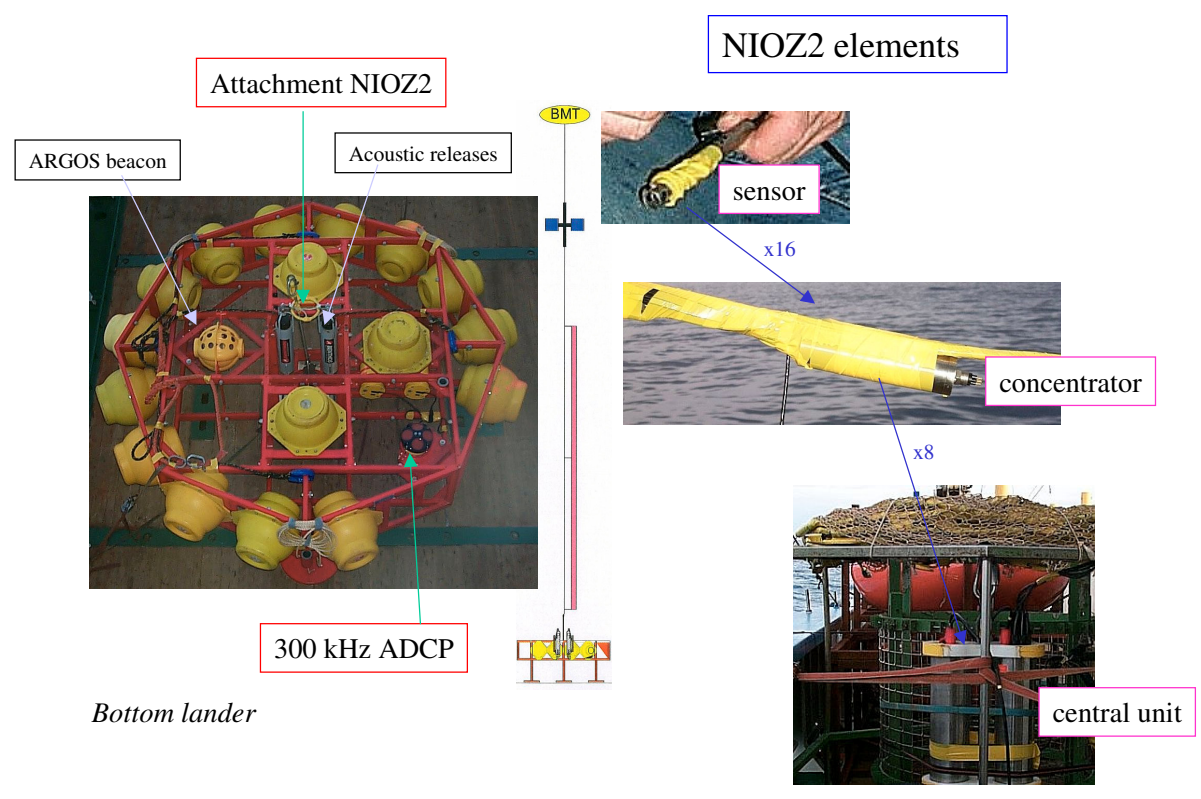

NIOZ2 coiled up on top Rosette frame

Fig. 2. Mooring configuration and NIOZ2 elements.

\section{Instrumentation}

\subsection{Technical aspects}

Comparing NIOZ2 with NIOZ1 several technical differences are noted (Table 1). NIOZ1 uses two thermistors that are both the R-parts of a certain type of RC-oscillator, a Wien(bridge) oscillator. This makes the temperature measurement actually a period measurement. The resolution of such measurement can be made very high and is independent of cable losses. In contrast, NIOZ2 operates a single thermistor at $0.3 \mathrm{~V} \mathrm{DC}$ in a Wheatstone bridge on a 24 bit $\mathrm{A} / \mathrm{D}$ convertor. This results in much less precision $\left(\sim 10^{-3^{\circ}} \mathrm{C}\right)$ compared to NIOZ1

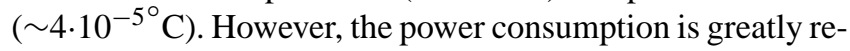
duced and sampling is truly synoptic. The processing time of all 128 thermistors is only $0.2 \mathrm{~s}$, so that sampling at a rate of $1 \mathrm{~Hz}$ is easily achieved inclusive of data transport and storage, which is 20 times faster than NIOZ1.

In NIOZ2, the glass embedded temperature sensitive semiconductor plus electronics board are held inside a pressure resistant titanium tube $13 \mathrm{~mm}$ in diameter and $120 \mathrm{~mm}$ in length (Fig. 2). The glass embedding ensures no effects of pressure up to at least $700 \mathrm{Bar}$ on the temperature measurement. The advantage of the titanium housing is less corrosion sensitiveness but the disadvantage is the greater difficulty in finding proper casting and primer materials to watertight the connections to the electric cables. Presently polyurethane resin is used ( 85 shore-A). To spread the risk of accidental leakage the entire string is split up into 8 sections of 16 sensors. Each section separately powers 4 groups of 4 sensors. Depending on the type of failure, one either looses data from
1,4 or 16 sensors at a time. This approach also allows for easy reconfiguration or replacement in the field. The drawback is the rather large amount of individual cables involved, which are kept as thin as possible $(0.003 \mathrm{~m})$. The 16 cables from the 16 sensors are led to one data concentrator and the 8 cables from the 8 data concentrators are led to a single central controller-datalogger-power supply unit.

The data are logged in portions of $10.5 \mathrm{Mb}$ on a $512 \mathrm{Mb}$ compact flash card using a Persistor CF-1 micro controller operating in PicoDos. The uploading of a full $512 \mathrm{Mb}$ memory card takes only about $40 \mathrm{~min}(200 \mathrm{Kbaud})$ via an USBport. As a fresh battery pack outlasts the filling of $512 \mathrm{Mb}$ by a factor of 1.5-2 (depending on the sampling rate), the total period of measurements depends on the capacity of the memory card and on the sampling frequency. The latter can be chosen between 0.033 and $1 \mathrm{~Hz}$. Although designed for short-term moorings whilst sampling at high frequency, NIOZ2 can be moored for up to 400 days whilst sampling once every $30 \mathrm{~s}$.

In NIOZ1 one could replace an individual sensor rather easily, but no cabling could be changed as it consisted of a single umbilical. In NIOZ2 one may replace one segment, that is 16 sensors and one concentrator, as the smallest interchangeable part. Each sensor's cable length can be modified individually. Presently, all electric cables, sensors and concentrators are taped to a $0.009 \mathrm{~m}$ nylon coated steel cable. The 128 sensors are fixed at $0.5 \mathrm{~m}$ distances. 
Table 2. Instrument details of ADCP-NIOZ2 mooring between 11 March 2003 and 16 March 2003 at $29^{\circ} 59.876^{\prime}$ N, $028^{\circ} 18.906^{\prime} \mathrm{W}$, $531 \mathrm{~m}$ depth. (ls = lowest sensor; $\mathrm{fb}=$ first bin).

\begin{tabular}{lcc}
\hline Instrument & depth (m) & Sampl. int. (s) \\
\hline Nortek AquaDopp & 445 & 30 \\
Aanderaa RCM11 & 446 & 60 \\
NIOZ2 & $528.15(\mathrm{ls})$ & 1 \\
RDI 300kHz ADCP & $529.75(\mathrm{fb}: 523.2)$ & 30 \\
\hline
\end{tabular}

\subsection{The mooring configuration}

The central steel cable assures that the thermistor string can be moored in line. Generally, the thermistor string is moored in conjunction with an upward looking $300 \mathrm{kHz}, \theta=20^{\circ}$ beam angle RDI-Sentinel ADCP mounted in a bottom landing frame (Fig. 2). Thermistor string motions are kept as low as possible $\left(<5^{\circ}\right.$ for currents up to $\left.0.4 \mathrm{~m} \mathrm{~s}^{-1}\right)$ by attaching the string under a single ellipsoidal buoy having $200 \mathrm{~kg}$ net buoyancy.

The ADCP measures all three components of current between $z=8-86 \mathrm{~m}(445-523 \mathrm{~m}$ depth). The Cartesian (East, West, Vertical) current components are transferred to (offslope, alongslope, bottom normal $)=(u, v, w)$ as in van Haren et al. (1994), with $z=0$ at the bottom for the thermistor stringADCP configuration (CTD observations will be referred to as depth from the surface). The ADCP cannot sample faster than once per $30 \mathrm{~s}$ as this would already fill its entire memory of $450 \mathrm{Mb}$ within 15 days.

Instead of the ADCP's tilt meter information, which gave a tilt of $6.7 \pm 0.05^{\circ}$, the bottom slope estimate of $\alpha=4.5 \pm 0.3^{\circ}$ from the ship's echo sounder is used. Although the ship's echo sounder has a relatively large foot print of $\sim 170 \mathrm{~m}$ at the mooring site, this larger scale information for determining the bottom slope is preferred above the ADCP's tilt information, because the former length scale is closer to the typical vertical scale of the boundary layer to be studied (see Sect. 3). Also we have no information on the precise situation of the lander with respect to small bottom structures such as boulders. Given the $4.5^{\circ}$ bottom slope and an expected local aspect ratio of $\mathrm{O}(0.01-0.1)$ the above coordinate transform implies an $\mathrm{O}(0.1-1)$ change in $w$ velocity as the transform from original $w_{\text {raw }}$ involves $w \sim w_{\text {raw }} \cdot \cos \alpha+u_{\text {raw }} \cdot \sin \alpha$.

The ADCP also provides an "error velocity" $e$ (van Haren et al., 1994),

$e=\frac{b_{1}+b_{2}-b_{3}-b_{4}}{4 \cos \theta}=$

$\frac{-\left(w_{1}+w_{2}-w_{3}-w_{4}\right)}{4}+\frac{\left(u_{2}-u_{1}-\left(v_{4}-v_{3}\right)\right) \tan \theta}{4}$,

where the sub-scripts "raw" are left out. Thus, $e$ is the difference in beam currents $b_{i}$ between beam pairs and indicative of the current inhomogeneity across the beam spread (and/or a failure of one or more beams). As a result, its data can be used to verify the level of significance of $w$ with respect to instrumental noise, because $w$ is defined as,

$$
\begin{aligned}
& w=\frac{-b_{1}-b_{2}-b_{3}-b_{4}}{4 \cos \theta}= \\
& \frac{w_{1}+w_{2}+w_{3}+w_{4}}{4}-\frac{\left(u_{2}-u_{1}+\left(v_{4}-v_{3}\right)\right) \tan \theta}{4} .
\end{aligned}
$$

It is noted that the system's output of $e$ has to be divided by a factor of $4 \cos \theta$ as indicated above to be comparable with $w$ (van Haren et al., 1994). It may be evident that $e$ can also be used to qualitatively investigate quasi-turbulent overturning motions varying on scales $<25$ m horizontally and $<$ several minutes in time.

Finally, the ADCP backscatter strength or echo intensity output $I$ is used as a qualitative measure for variations in acoustic reflectances such as suspended material and turbulence and small-scale stratification. Instead of using the raw data that include the water attenuation of sound, and instead of using a rather imprecise general formula that accounts for this water attenuation, the mean at each depth is subtracted: the relative echo intensity $d I$.

As will be apparent from the observations in Sect. 3 the amount of scatterers posed a problem on the data analysis: in general the signal to noise $(\mathrm{s} / \mathrm{n})$ ratio was low, presumably due to clear water. As a result, it was impossible to perform spectral analysis and direct estimates of heat and momentum fluxes were unreliable, also because of the large mismatch in resolved scales between NIOZ2 and the present ADCP. Furthermore, at some vertical positions like at $z=19 \mathrm{~m}$ the data were flawed by the zero-bias due to reflection off NIOZ2, which is attached to the centre of the bottom lander, with a $1 \mathrm{~m}$ horizontal off-set with respect to the central vertical axis of the ADCP (Fig. 2). The latter does "hear" NIOZ2, because this string is more bulky than a standard thermistor string due to its concentrators and large number of cables. Such unwanted reflections could have been partially avoided when the ADCP were gimballed in the frame. However, the ADCP is not gimballed in the frame, because a frame tilted at a sloping bottom or with one leg at a single boulder may cause one or more beams to reflect at the frame, as the ADCP is mounted inside the frame to prevent entanglement with the thermistor string during deployment.

The bottom lander mooring is recovered using two Benthos acoustic releases mounted in the frame, which uncouple simultaneously the thermistor string and the main $500 \mathrm{~kg}$ dropping weight from the bottom frame, so that the thermistor string and the bottom lander surface separately.

\section{First results}

The bottom lander mooring was located near the top of the eastern slope of GMS, Canary Basin (CB), North-Atlantic 

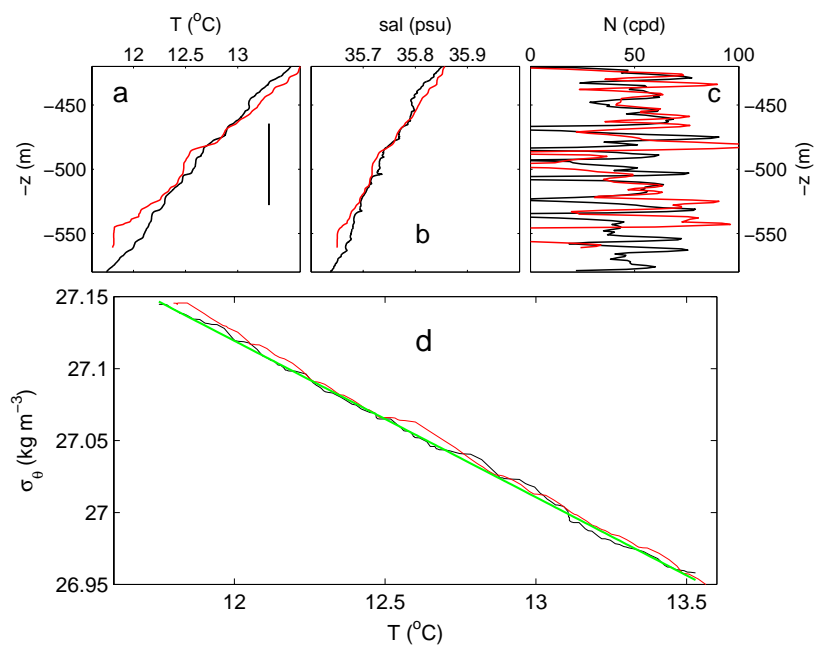

Fig. 3. Environmental conditions from CTD01 $(24 \mathrm{~Hz}$ raw data; black) and from CTD02 (2 m smoothed; red) (Fig. 1) around the depth of NIOZ2 (vertical bar in (a) indicates the range). (a) Temperature. (b) Salinity. (c) $N$ computed over $5 \mathrm{~m}$ intervals. (d) Temperature-density anomaly plot with the corresponding linear relationship for CTD01 in green.

ocean (Fig. 3; Table 2). The mooring was deployed for $\sim 5$ days due to limited shiptime. The NIOZ2 recorder collected $185 \mathrm{Mb}$ of $1 \mathrm{~Hz}$ data from about $500 \mathrm{~m}$ depth. The mooring was not deployed deeper, because during the predeployment calibration the aforementioned casting material showed problems at pressures greater than about 200 Bar. Also, ADCP-data become poor when the instrument is moored at angles of more than $15^{\circ}$. As GMS is very steep with typical slopes of $10-20^{\circ}$ or more, a suitable slope was only found near the foot of the underwater mount at $\sim 4500 \mathrm{~m}$ depth and near its top between $450-550 \mathrm{~m}$ depth. The observed ADCP's tilt angle of $6.7^{\circ}$ ensured good current data. The current meter immediately above the thermistor string showed typical tilt of $1.5^{\circ}$, with a maximum of $4.4^{\circ}$. As a result, vertical (horizontal) excursions of a NIOZ2 sensor halfway the string were typically $0.06(1.5) \mathrm{m}$, and maximum 0.15 (4) m, respectively.

Upon recovery it was found that 3 complete segments of NIOZ2 had leaked and failed, and that several other sensors had failed as well. As a result, specific quantitative computations were limited due to this failure of sensors. For example, computation of Thorpe scales was more difficult than anticipated given the limited vertical ranges of good data. Nevertheless, this first field experiment provided detailed temperature observations of internal waves and large non-linear bores.

\subsection{Observed environmental interior conditions}

The upper ocean of the $\mathrm{CB}\left(\sim 30^{\circ} \mathrm{N}, 22^{\circ} \mathrm{W}, 5000 \mathrm{~m}\right.$ depth) shows a variable rather than a smooth temperature and salin-

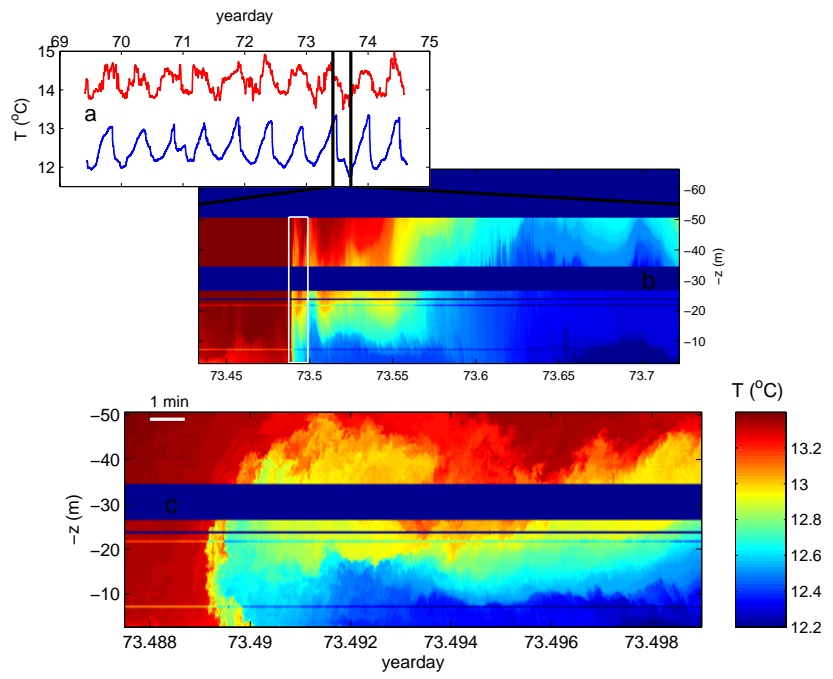

Fig. 4. (a) Time series of temperature during the entire mooring period measured by the ADCP at $z=1.25 \mathrm{~m}$ and by the AquaDopp current meter moored above NIOZ2 thermistor string at $z=86 \mathrm{~m}$. (b) Detail of $10 \mathrm{~h}$ of NIOZ2 temperature demonstrating a sharp nearbottom front. The blue bar above $z=52 \mathrm{~m}$ indicates two failing segments, the brown bar around $z=30 \mathrm{~m}$ one failing segment; otherwise 3 sensors were bad as well. The white rectangle indicates panel (c). Further detail of $17 \mathrm{~min}$ of NIOZ2 data around the passage of the front.

ity change with depth, also in the range of interest here (Fig. 3). This small-scale variability in CTD-profiles suggests internal wave induced straining and occasional overturning. This is observed in profiles obtained above the abyssal CB away from boundaries, as well as for profiles obtained above rugged topography like GMS. It is noted that near-bottom overturning and stratification vary considerably with time. Sometimes, stratification moves very close to the bottom, as can be seen with some difficulty in Fig. 3a (red curve), where it is only $1 \mathrm{~m}$ from the lowest level in the profile, or about $4 \mathrm{~m}$ from the bottom.

The CTD profiles around the depth range of the deployed NIOZ2, demonstrate a slight difference between GMS and the abyssal CB. This results in a slight change in large-scale temperature and salinity variation up to $150 \mathrm{~m}$ above the bottom, or several $\mathrm{km}$ horizontally. This affects the "largescale" stratification. In the open ocean $N$ (computed over $5 \mathrm{~m}$ ) has a value of $45 \pm 15 \mathrm{cpd}$ over the depth range in Fig. $3 \mathrm{c}$, although strongly varying between $0-80 \mathrm{cpd}$ due to the small layers. As shown in Fig. 3c, $N(450 \mathrm{~m})=50 \pm 20 \mathrm{cpd}$ observed above GMS, decreasing to $N(500)=20 \pm 15 \mathrm{cpd}$ and increasing again to $N(535)=60 \pm 20$ cpd before becoming negligibly small, except near the bottom. This greater variability, also at large scales, near GMS may be related to typical sloping bottom processes and internal waves.

The CTD-profiles from different locations around the mooring site did not result in great differences in temperature-potential density anomaly $\left(\sigma_{\theta}\right)$ relationship. 


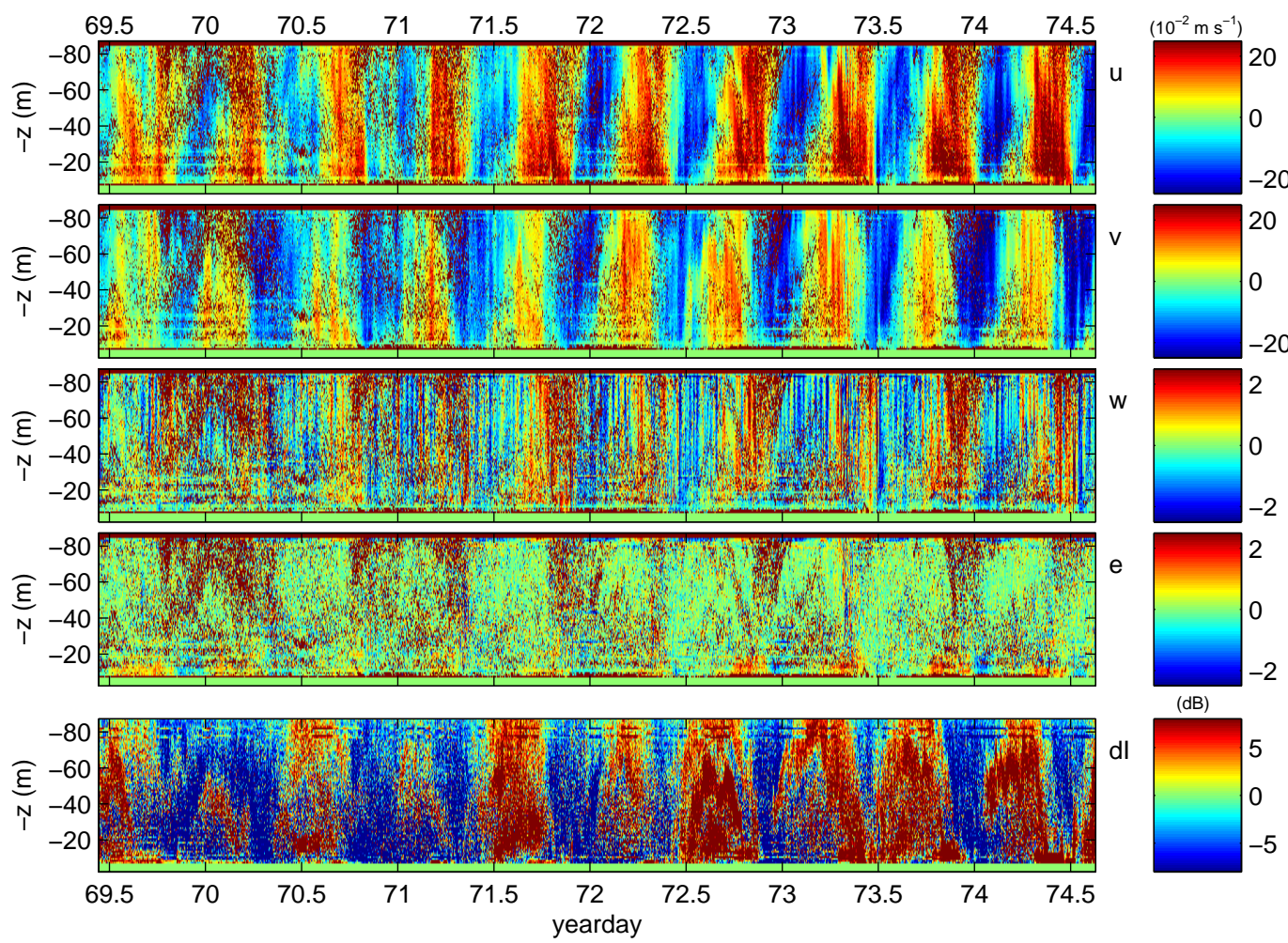

Fig. 5. Overview of ADCP observations between $z=7.8-86.8 \mathrm{~m}$. In addition to the three current components cross-slope $(u)$, along-slope $(v)$ and bottom-normal $(w)$ the corrected "error" velocity $(e)$ and the relative echo intensity $(d I)$ are shown. The brown speckles throughout the graphs indicate "bad data", of which there are many.

Over the depth range between $420-580 \mathrm{~m}$ depth, which is slightly expanded with respect to the NIOZ2 depth range to cover the entire temperature range sampled by NIOZ2, $\delta \sigma_{\theta}=-0.108 \pm 0.002 \delta \mathrm{T} \mathrm{kg} \mathrm{m}^{-3}$ (Fig. 3d). As salinity decreased with depth it counteracted the temperature induced density gradient. Some of observed deviations from this linear relationship were due to mismatches of the CTD sensors that were difficult to mend even in post-processing. The remainder of the mismatches was due to the environment that varied with time, with density steps and homogeneous layers alternating quickly. Although homogeneous layers of several meters in the vertical were abundant (Sect. 3.3.2), the variations with time caused some problems for the in-situ calibration of NIOZ2 (Appendix A).

3.2 General temperature and current observations near the bottom of GMS

\subsubsection{General temperature observations}

An overview of the entire record demonstrates the great variability of temperature in the bottom boundary layer above the $4.5^{\circ}$ slope near the top of GMS (Fig. 4a). This slope is much less than the slope of $\sim 1.6^{\circ}$ of semidiurnal internal tidal wave characteristics for typical interior stratifica- tion and we do not expect internal tidal generation or critical reflection at this site. Nevertheless, the main variability has a semidiurnal tidal periodicity and a considerable discrepancy is observed across the vertical, as can be inferred from current meter temperature sensors at $z=1.25$ and $86 \mathrm{~m}$ that span a larger range than NIOZ2. Away from the bottom many small-scale temperature fluctuations are superimposed on the tidal signal. Very close to the bottom the record is much smoother, but the non-linearity seems larger than further up as is visible from the cnoidal shape of the tidal record, with occasional sharp ramps like near day 73.5. In detailed NIOZ2 observations like in Figs. $4 \mathrm{~b}$ and $4 \mathrm{c}$ it appears that this ramp is extremely sharp, with a front passing the sensors with temperature dropping by $0.5^{\circ} \mathrm{C}$ within $1 \mathrm{~s}$. Such fronts or bores have been observed previously, in data sampled at a rate of once/30 s above the continental slopes of the Faeroe-Shetland Channel, where they appeared at a 4 days periodicity (Hosegood et al., 2004), and the Bay of Biscay, where tidal periodicity dominated (Gemmrich and van Haren, 2001). Apparently, such roaring, upslope motions resulting in strongly non-linear temperature records also exist at the sides of seamounts in the open ocean.

Preceding and following such frontal passage, nearbottom temperature stratification varied considerably, although completely homogeneous bottom boundary layers 


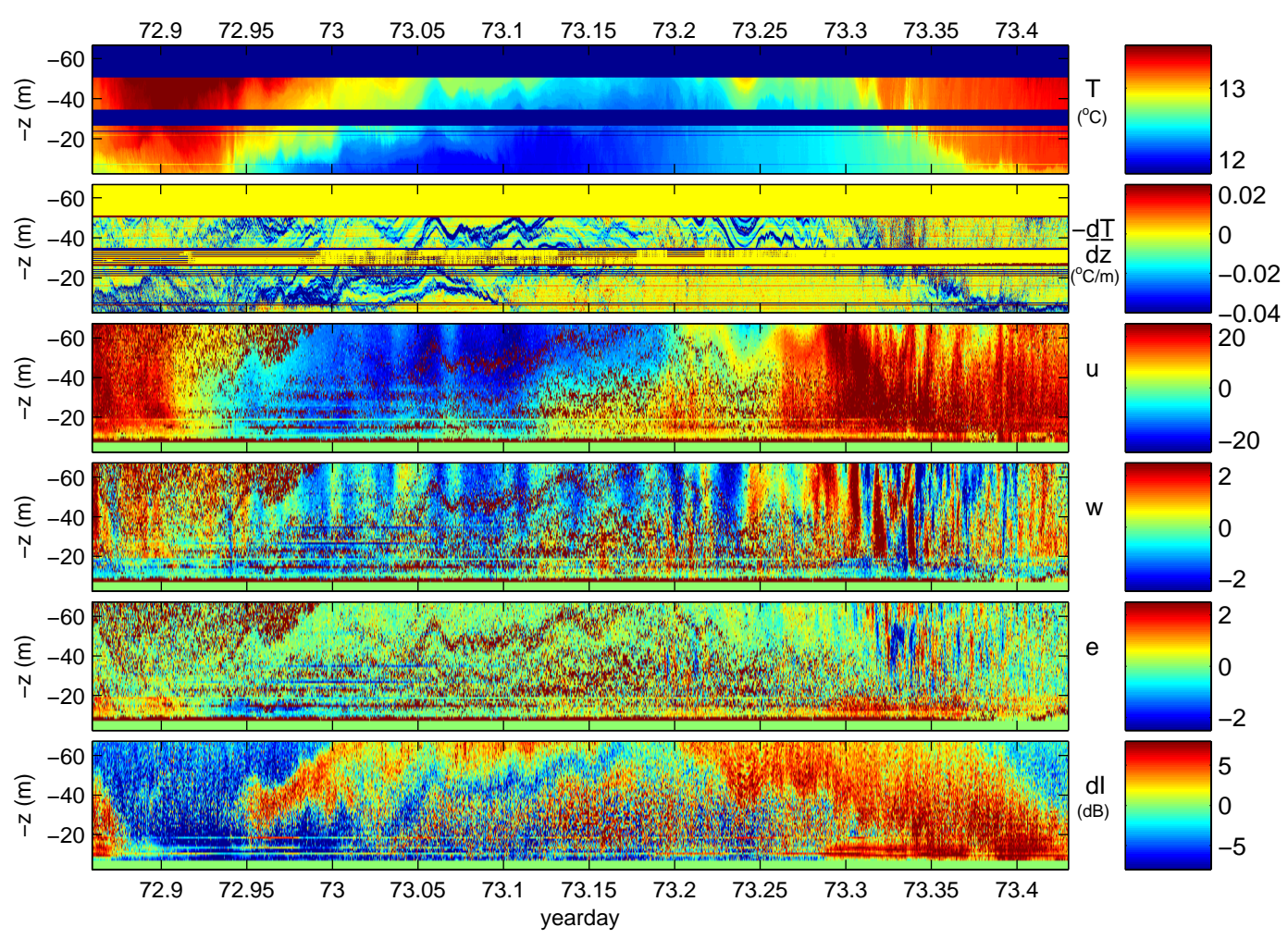

Fig. 6. A typical tidal period of ADCP and NIOZ2 observations between $z=2.8-66.8 \mathrm{~m}$. In $\partial T / \partial z$ blue-green indicates stable stratification, yellow indicates neutral and orange-red indicates unstable overturning.

of several tens of meters thick as in flat-bottom tidal seas were not observed. With the varying stratification many small-scale features were observed ranging from overturns (Sect. 3.3.3) to high-frequency internal waves (Sect. 3.3.4). The latter varied from waves having an apparent periodicity of 30-60 s, for example at day 73.62, and smooth $15-\mathrm{min}$ waves, which is of the order of the local buoyancy period, e.g. around day 73.7 .

\subsubsection{General current observations}

Like temperature, the near-bottom currents and relative echo intensity are also dominated by semidiurnal tidal variations (Fig. 5). As is obvious from the currents, the observations start just after neaps and stop just before springs. The cross-slope current generally has a slightly larger amplitude than the along-slope tidal current, which has been modelled and observed before (Fig. 1; Mohn and Beckmann, 2002). Apparently, the seamount does not steer the largescale ( "barotropic") tidal current. These tidal currents are also not uniform in the vertical, with strongest currents observed usually, but not always, not too far off the bottom ( $z \sim 10-20 \mathrm{~m})$. Additionally, strong high-frequency $(\sim N)$ variability is observed, during which relatively large bottomnormal currents $\mathrm{O}\left(10^{-2} \mathrm{~m} \mathrm{~s}^{-1}\right)$ are observed (the vertical striping in the $w$ panel). The lack of coherence between $e$ and $w, e$ being generally much smaller than $w$, implies confidence in measured $w$ over scales larger than the beam spread $\mathrm{O}(10 \mathrm{~m})$, because this implies that the horizontal current inhomogeneity over the beam spread is much less than the actual bottom normal current (see definitions in Sect. 2.2). Each tidal period has its own characteristics, with varying amplitudes and height of tidal and high-frequency motions and echo intensity.

\subsection{Detailed observations near the bottom of GMS}

\subsubsection{A tidal period}

An example of a single tidal period (Fig. 6) shows the common features, of which the details may vary during other tidal periods, 1 . asymmetry in $u-$ (and $v-$, not shown) currents with height, with near-bottom currents always leading those higher up, 2. a sudden transition to upslope motion and a smooth transition to downslope motion as in Hosegood et al. (2004), 3. many high-frequency waves in both $u$ and $w$, but not in $e$. Such waves exist up to $z=80 \mathrm{~m}$ and they have periods of typically $\sim 2 T_{N}, T_{N}$ denoting the large-scale buoyancy period, as observed previously in the North Sea (van Haren et al., 2001), 4. these high-frequency motions are internal waves as is evident from the high-resolution temperature measurements (especially from the panel on $\partial T / \partial z$, 


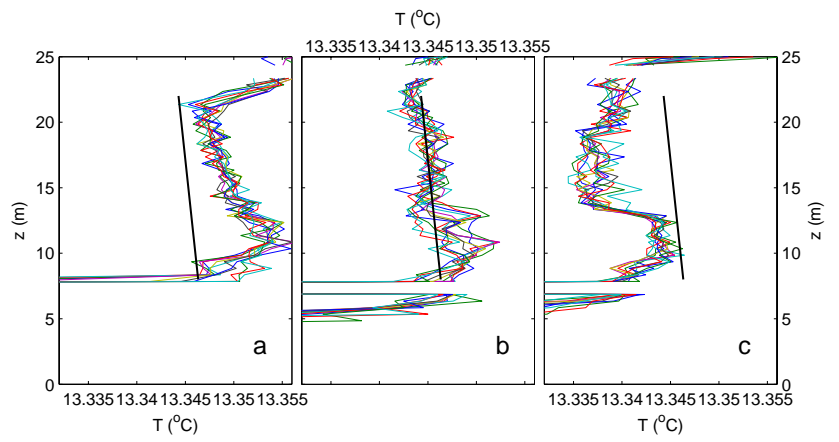

Fig. 7. NIOZ2 sensor stability in near-homogeneous layers. In each panel colours indicate $10 \mathrm{NIOZ} 2$ profiles, or $10 \mathrm{~s}$ of data, with in black the local adiabatic lapse rate. (a) $40 \mathrm{~s}$ before panel (b). $5 \mathrm{~s}$ before $-5 \mathrm{~s}$ after day 73.4868. (c) 40 a later than panel (b).

which demonstrate that a weakly stratified layer, not a homogeneous bottom boundary layer, may extend up to $\mathrm{z} \sim 40 \mathrm{~m}$ later in the up-slope phase of the tide, but also that stratification is capping a very thin bottom boundary layer of less than $5 \mathrm{~m}$ during the up- and down-slope phases. Especially during the down-slope phase (between days 73.3-73.4) $e$ is non-negligible with respect to $w$, which is evidence of substantial current inhomogeneity across the beam spread. This current inhomogeneity seems to reflect small-scale motions, and during this period most overturns are observed in the NIOZ2 data, with the exception of the period when a tidal bore passed at the start of the upslope phase. A coarse estimate of Thorpe overturning scales during such period of enhanced current inhomogeneity yields $K=8 \pm 4 \cdot 10^{-4} \mathrm{~m}^{2} \mathrm{~s}^{-1}$, whilst values are estimated between $3 \cdot 10^{-4}-3 \cdot 10^{-2} \mathrm{~m}^{2} \mathrm{~s}^{-1}$, during brief periods at the start of the upslope phase.

\subsubsection{Sensor stability: performance of NIOZ2 in near- homogeneous layers}

Periods of very weak stability or near-homogeneous waters offered the chance to investigate the stability of the NIOZ2 sensors and to verify the accuracy obtained from the calibration post-calibration adjustment (Appendix A). Such periods occurred above the sloping bottom of GMS, but generally away from the lowest sensors and for relatively brief periods of time only. During a tidal period such periods usually occurred twice, once well into the upslope phase, for example around day 73.62 between $z=20-40 \mathrm{~m}$ (not shown), and towards the very end of the downslope phase, for example around day 73.487 at several depths between $z=8$ $25 \mathrm{~m}$ (Fig. 7). In both cases near-homogeneity lasted for about $15-60 \mathrm{~s}$ at a particular depth. Near-homogeneity or neutral stability was assumed when a negative temperature gradient was observed, which approached the adiabatic lapse rate $\Gamma=-1.45 \pm 0.01 \cdot 10^{-4{ }^{\circ}} \mathrm{C} \mathrm{m}^{-1}$ in Fig. 7 . The observed temperature profile has a significant negative slope and approaches $\Gamma$ between $z=14-20 \mathrm{~m}$ in Fig. $7 \mathrm{~b}$ and $z=9-13 \mathrm{~m}$ in

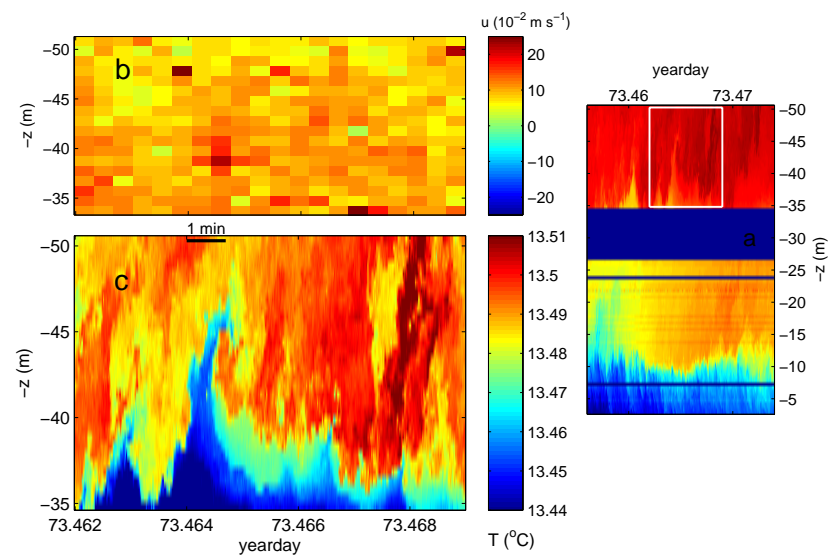

Fig. 8. Example of detailed observation of an overturn, $\sim 12 \mathrm{~m}$ breaking wave around $z=40 \mathrm{~m}$ during the downslope phase of the tide. (a) Corrected data showing temperature stratification and very high-frequency $(\sim 1 \mathrm{~min})$ temperature variations down to the sensors closest to the bottom. (b) Detailed period (indicated by rectangle in (a)) of ADCP's u-current. (c) From the white rectangle in (a) showing a large Kelvin-Helmholtz overturning (Turner, 1973).

Fig. $7 \mathrm{c}$, or across $\sim 10$ independent sensors each time. This suggests a much greater stability of $\sim 10^{-4^{\circ}} \mathrm{C}$ of the NIOZ2 sensors, and the relatively poor accuracy is entirely due to the calibration procedure, so that improvement is suggested for manual adjustment of the calibration (Appendix A). Further examples of detailed observations are given after application of such adjustment to the calibration using the sensors' stability.

\subsubsection{Temperature overturns}

NIOZ2 revealed the character of some of the occasional small-scale temperature overturns during the downslope phase of the tide (Fig. 8). Such overturns appeared in a more or less regular sinusoidal waveform in a temperature time series, but they were related to a breaking wave or rolling-up of a Kelvin-Helmholtz overturn (Figs. 8a and 8c). Although such overturning waves have been observed in the ocean at shallow depths using photography (Woods, 1968), laboratory experiments (examples in Turner, 1973), temperature profiling (Thorpe and Hall, 1974) and detailed acoustic backscatter (Orr and Mignerey, 2003; Moum et al., 2003), the present observations are the first detailed observations of such overturn at great depth. As the overturn is poorly resolved and not recognizable in the ADCP data (Fig. 8b), which are sampled "only" once per $30 \mathrm{~s}$ resolving "only" $\mathrm{O}(10 \mathrm{~m})$ horizontally and $1 \mathrm{~m}$ vertically, such NIOZ2 observations emphasize the need to sample at high frequency to capture such processes.

The large-scale overturn, backwards breaking as in Turner (1973), of more than $10 \mathrm{~m}$ in height, and the associated very thin layers of enhanced stratification of $\sim 1 \mathrm{~m}$, take about 2 min to pass the sensors. Several are observed in Fig. 8a, be- 


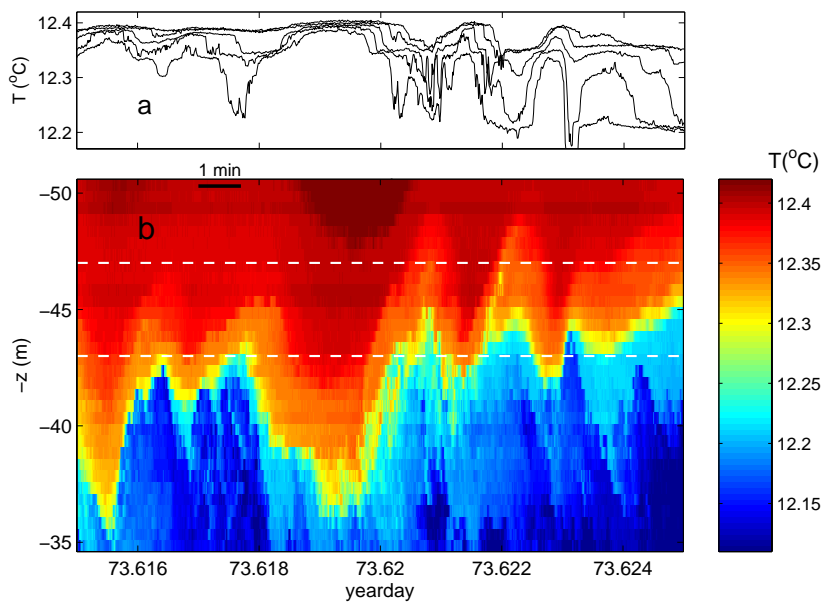

Fig. 9. Example of NIOZ2 observations of very high-frequency internal "wave" during the upslope phase of the tide. (a) temperature from 5 sensors at $1 \mathrm{~m}$ intervals between the white dashed lines in (b). Contour plot using information of all sensors in the depth-time interval shown.

tween $10-20 \mathrm{~m}$ around day 73.458 and also in the white rectangle, which is Fig. 8c. As u $\sim 0.1 \pm 0.05 \mathrm{~m} \mathrm{~s}^{-1}$ and assuming the phase speed $c \sim u$, the horizontal length scale of the overturn is $\sim 10 \mathrm{~m}$. These horizontal length scale estimates are half an order of magnitude smaller than those observed by Orr and Mignerey (2003) and Moum et al. (2003), whilst the vertical length scales are similar. The latter authors also observed intensification of acoustic backscatter in layers of $\sim 0.5-1 \mathrm{~m}$ thickness, suggesting similar overturning in these layers as well. Such scales are barely resolved by the present observations, but small-scale variations $\mathrm{O}(1-10 \mathrm{~s}), \mathrm{O}(1-5 \mathrm{~m})$ are visible in the NIOZ2 observations (Fig. $8 \mathrm{c}$ ).

\subsection{4 (Too) short internal waves}

The above fast sampling is not only required for large-scale 'turbulent' motions, but also for small-scale waves. NIOZ2 also revealed occasional "regular" small-scale temperature variations (Fig. 9) that appeared to have periods of $\sim 3 \mathrm{~min}$, much less than the local buoyancy period of $20-30 \mathrm{~min}$ $(N=50-70 \mathrm{cpd}$ ) (Fig. 3c), no matter how small the vertical length scale was chosen to compute $N(z)$. Figure 9 shows the instrumental capability in the occasionally very smooth temperature records hiding the $0.5-1 \cdot 10^{-3^{\circ}} \mathrm{C}$ noise and the occasionally quite "noisy" environmental background, with noise levels of $\mathrm{O}\left(10^{-2}{ }^{\circ} \mathrm{C}\right)$, especially also during the passage of a wave (e.g. between days 73.6185-73.62). The smooth waves have a period of $\sim 3 \mathrm{~min}$, whilst the noisy motions are also periodic (e.g. around day 73.621, with period of $\sim 10 \mathrm{~s}$ ). These smooth waves are tilted at an angle to the vertical. If such waves existed as free propagating internal gravity waves their upward "phase" propagation would imply downward energy propagation. However, their ob-

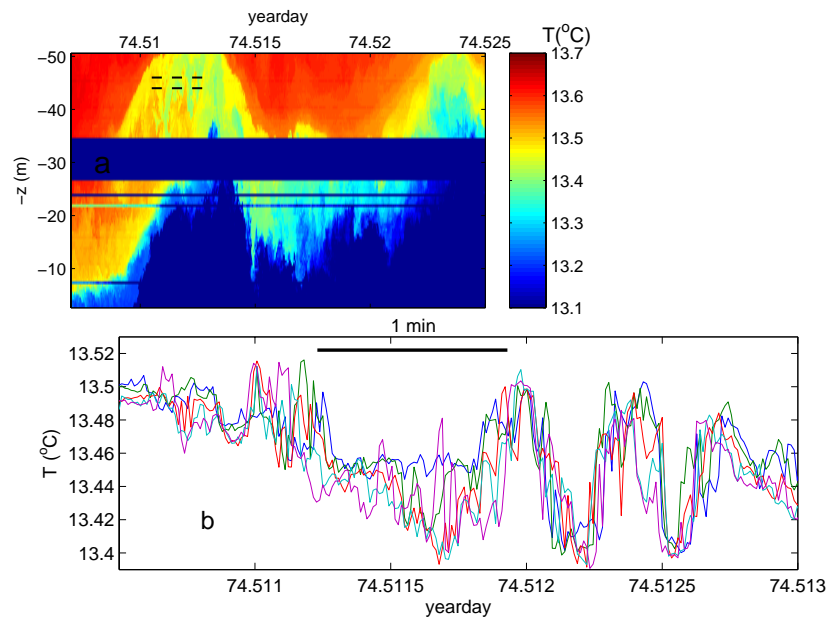

Fig. 10. Example of NIOZ2 observations of very high-frequency internal "wave" and occasionally unstable fluid during the upslope phase of the tide. (a) Contour plot showing lower temperature water (green; between days 74.51-74.514; $38<z<50 \mathrm{~m}$ ) in an environment of warmer water under the crest of a large-scale wave, which has a period near the local buoyancy period. The dashed black lines of the small-scale "wave" indicate the depth levels and time range of the temperature series in (b).

served frequency $\sigma_{o} \gg N$. Computing the intrinsic frequency $\sigma=N=\sigma_{o}-U \cdot k, U \approx 0.15 \pm 0.05 \mathrm{~m} \mathrm{~s}^{-1}$ and $k$ the horizontal wavenumber, we require for free internal waves a wavelength $\lambda=2 \pi / k \approx 2 \pi U / \sigma_{o}=27 \pm 9 \mathrm{~m}$. Apparently the short waves are generated and Doppler shifted by the larger scale internal waves. They appear as interfacial waves and they may generate turbulence as they "move" at the fringe of breaking.

This can also be seen in a second example of even smaller scale smooth waves, which have periods of less than $1 \mathrm{~min}$, and which are "carried" below the crest of a wave having an $\sim 18$ min period, close to the buoyancy period (Fig. 10). NIOZ2 is capable of resolving both the $30 \mathrm{~s}$ "wave", as well as coherent and incoherent motions within that small wave, which both exist as cool water intrusions under the carrier wave. It may be obvious that these small-scale waves are not visible in the ADCP data, not just because they are not resolved in time, but especially also because they have horizontal length scales that are comparable to beam spread over which currents are averaged. Resolving currents for these phenomena thus requires other current devices than an acoustic profiler.

\section{Summary}

We have presented some data from a newly built thermistor string, which is capable of measuring temperature variations in the deep ocean at an estimated precision better than $1.5 \cdot 10^{-3{ }^{\circ}} \mathrm{C}$, whilst sampling 128 sensors synchronously at a rate of $1 \mathrm{~Hz}$ for a period of up to 15 days potentially at 


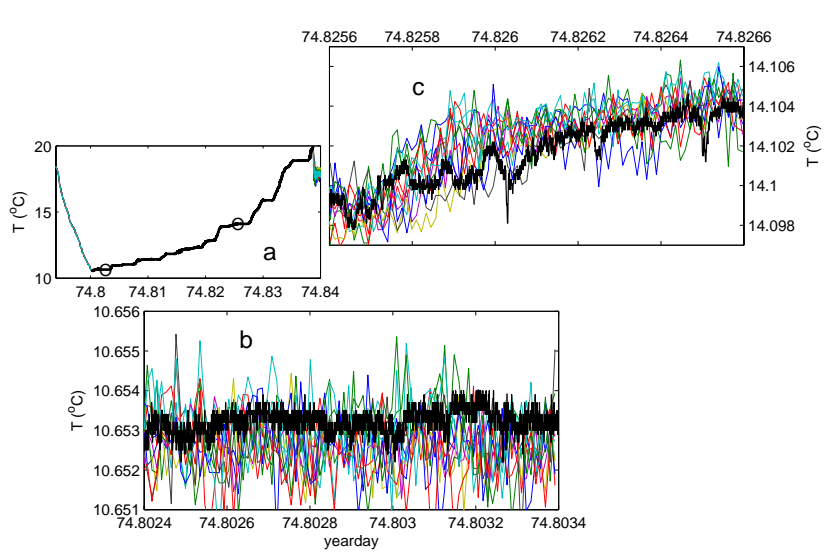

Fig. 11. In situ calibration of NIOZ2 using CTD. (a) Calibrated NIOZ2 temperatures from 10 sensors (colours), and upcast trace of CTD (black) demonstrating the 9 steps between $10.5-18.8^{\circ} \mathrm{C}$ when the CTD is held still in a layer of "constant" temperature. (b), (c) (different scales) Noise or precision comparison with environmental small-scale variability of $86 \mathrm{~s}$ of the record in (a) (circles), which demonstrate the 3 times higher noise rate of the NIOZ2 sensors compared to the CTD-temperature sensor, but also some of the relatively large environmental variability in $\sim 20 \mathrm{~s}$ waves.

depths down to $6000 \mathrm{~m}$. During the construction and first trials the sensors turned out very robust, but a major problem was found in the proper bonding of polyurethane casting resin to titanium.

The response and sampling time in combination with its endurance have opened new capabilities for studies on internal waves, e.g. near sloping bottoms, up to the highest frequencies, including non-linearities like internal bores. The latter appear irregularly at a relatively large time scale of several hours-days, but pass the sensors within a few minutes. This is not different at GMS, where the tidal variability seems dominant, but the amplitude of such bores is modulated with a much longer timescale. As the importance of internal wave induced mixing is more and more recognized, also in conjunction with large-scale ocean circulation, detailed studies are needed to learn more about such mixing processes. Previously, detailed studies have been performed in laboratory experiments (e.g. McEwan, 1983) or near the surface of the ocean (e.g. Woods, 1968; Marmorino et al., 1987; Moum et al., 1992), but very limited in the deep ocean (Thorpe, 1987). Especially the transfer of energy from the large scale to the small mixing scales was difficult to explore with deep-ocean observations. In the examples given in this paper clearly the Doppler-shift of small internal waves to the point of breaking is observed, as well as shear-induced Kelvin-Helmholtz overturning. The appearance of bores during the upslope phase of the tide remains a subject of study, especially also because we have not yet established the underlying reason why the magnitude of a bore varies so strongly between the different (tidal) periods. Future investigations will also focus on
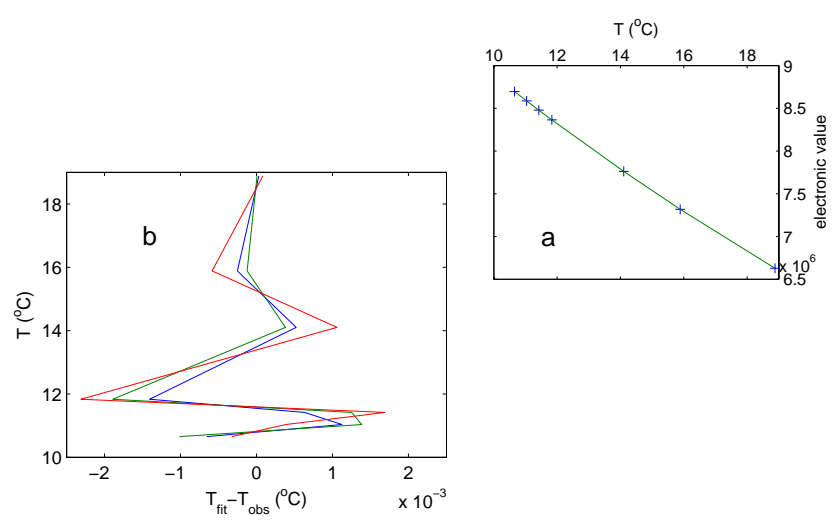

Fig. 12. (a) Polynomial fit of NIOZ2 raw data to 7 CTD temperature values following in situ calibration. (b) Residual of the fit (with mean $\mathrm{std}=1.3 \cdot 10^{-3^{\circ}} \mathrm{C}$ ).

small-scale fronts and homogeneous layers as resolved by NIOZ2.

\section{Appendix A: Calibration of NIOZ2}

As the digital representations of the data are non-linearly related to temperature, noise level is also a function of temperature, ranging from $4 \cdot 10^{-4^{\circ}} \mathrm{C}$ at $0^{\circ} \mathrm{C}$ to $1 \cdot 10^{-3^{\circ}} \mathrm{C}$ at $40^{\circ} \mathrm{C}$. Due to this non-linearity a precise calibration of each of the thermistors is required to achieve an accuracy of $<5 \cdot 10^{-3^{\circ}} \mathrm{C}$. A "best achievable" laboratory calibration takes months and is a complicated activity, whilst the accuracy is not better than $3 \cdot 10^{-3^{\circ}} \mathrm{C}$ (van Haren et al., 2001). As a result, like NIOZ1, NIOZ2 is calibrated in situ immediately before and after a deployment using a high-performance CTD: a much faster calibration.

The thermistor string is coiled up on top of the Rosettesampler protective cage surrounding a Seabird-911 plus CTD. The temperature sensor of the CTD is accurate to within $1 \cdot 10^{-3^{\circ}} \mathrm{C}$, with a polynomial deviation of $<1 \cdot 10^{-4{ }^{\circ}} \mathrm{C}$ and initial stability of $2 \cdot 10^{-4{ }^{\circ}} \mathrm{C}$ that can vary up to $2 \cdot 10^{-4^{\circ}} \mathrm{C}$ per month. The distance between the CTD-temperature and pressure sensors and the thermistor string is about $1 \mathrm{~m}$. During the upcast the CTD is commanded to depths of layers of near-homogeneous water, which are selected during the downcast (Fig. 11). As these layers move constantly up- and down, or are modified by internal wave straining and mixing, the requirement is that the temperature varies less than $1 \cdot 10^{-3^{\circ}} \mathrm{C}$ for a period of at least $90 \mathrm{~s}$. Therefore, CTD's temperature and pressure values are constantly monitored visually, which is not always always achieved satisfactorily (Fig. 11). Flushing of water passed the coiled up thermistor string seems reasonable as we did not see much trend in the record of individual sensors, and in comparison with those of other sensors, greater than the instrumental noise level of

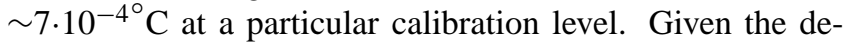


gree of non-linearity of the sensors 6-8 calibration values are sought, in this case over a range between $10.6-18.8^{\circ} \mathrm{C}$. The electronic NIOZ2 data are translated to temperatures using a third order polynomial fit to the calibration values for each sensors separately (Fig. 12). The standard deviation of this polynomial fit was between $1.2-1.5 \cdot 10^{-3}{ }^{\circ} \mathrm{C}$, resulting in an overall accuracy of $\sim 5 \cdot 10^{-3^{\circ}} \mathrm{C}$. The above procedure takes about $3 \mathrm{~h}$ for calibration around $2000 \mathrm{~m}$ depth.

In general, the result of this in-situ calibration is not much better than the laboratory calibration, due to the environmental variability, mooring frame vibrations and flow obstructions. This may also be inferred from the variability in CTD temperature, with standard deviations varying between $2-8 \cdot 10^{-4^{\circ}} \mathrm{C}$, all larger than the instruments' stability, at the different calibration levels (Fig. 11). However, because the NIOZ2 sensors are much more stable (see example in Sect. 3.3.2), post-processing can provide an accuracy close to the $1 \cdot 10^{-3^{\circ}} \mathrm{C}$ precision (Fig. 13). This requires two more processing steps after calibration.

First, profiles of mean temperatures are computed over small periods of time $\left(\sim T_{N}\right.$, the local large-scale buoyancy period) in which temperature is reasonably constant. These profiles are manually corrected to a new mean of a static stable temperature profile (Fig. 13a) under the assumption that overturns and small-scale instabilities are removed when averaged over such period. In practice, the corrections are constant shifts in temperature (Figs. 13b and 13d) and generally $<5 \cdot 10^{-3^{\circ}} \mathrm{C}$ (Fig. 13a), confirming the calibration accuracy. They are attributed to the difficulty of holding the calibration CTD long enough in constant temperature waters (Fig. 11). This is concluded as this correction is valid each time the particular correction temperature is reached during the entire period of observations. This first step is sufficient for an accuracy to within $1 \cdot 10^{-3}{ }^{\circ} \mathrm{C}$ over a short period of time (Figs. 13c and 13e). However, when this accuracy is required for the entire record, that is for the entire temperature range observed, a second post-calibration step can be used that also accommodates for the non-linearity of the sensors.

Over the entire temperature range of the record some 610 correction profiles as in Fig. 13 are then constructed. The calibrated data record is corrected by linear temporal interpolation and replacing the means by the static stable means for each particular temperature in each sensor.

Acknowledgements. We thank the crew of the R. V. Pelagia for deploying the "mixBB" bottom lander. We thank participants of the yellow tape-team, who taped NIOZ2 several times to its strength member: T. Hillebrand, K. Veth and P. Hosegood. M. Hiehle composed Fig. 1. The development of the NIOZ thermistor strings and the deployment in the Canary Basin were financed by investment grants ("Oceanographic equipment" and "LOCO", respectively) from the Netherlands organisation for the advancement of scientific research, NWO.

Edited by: M. Tomczak

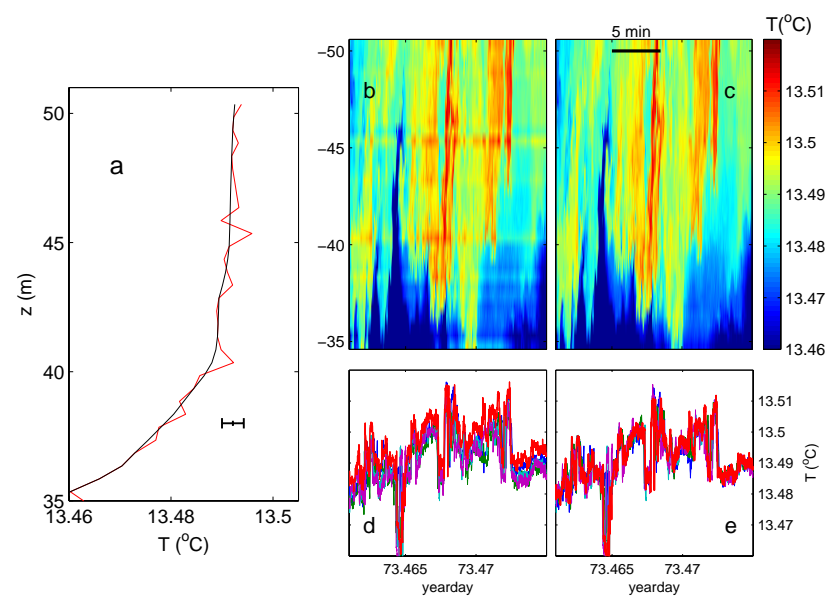

Fig. 13. Example of post-calibration processing of NIOZ2. (a) Mean profile for 32 sensors of the data portion in (b): uncorrected in red and "corrected" in black. The horizontal bar indicates

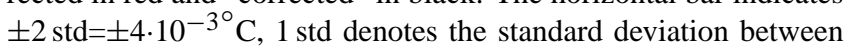
the profiles. (b) Uncorrected $22 \mathrm{~min}$ of data. (c) As (b), but replacing the observed mean with the corrected from (a). (d) Four temperature traces from (b) observed between $z=45-47 \mathrm{~m}$. (e) As (d), but corrected, demonstrating that the trace at $z=46 \mathrm{~m}$ is no longer displaced with respect to the others.

\section{References}

Alford, M. H. and Pinkel, R.: Observations of overturning in the thermocline: the context of ocean mixing, J. Phys. Oceanogr., 30, 805-832, 2000.

Brandt, P., Rubino, A., Quadfasel, D., Alpers, W., Selschopp, J., and Fiekas, H.-V.: Evidence for the influence of Atlantic-Ionian stream fluctuations on the tidally induced internal dynamics in the Strait of Messina, J. Phys. Oceanogr., 29, 1071-1080, 1999.

Gemmrich, J. R. and van Haren, H.: Thermal fronts generated by internal waves propagating obliquely along the continental slope, J. Phys. Oceanogr., 31, 649-655, 2001.

Hosegood, P., Bonnin, J., and van Haren, H.: Solibore-induced sediment resuspension in the Faeroe-Shetland Channel, Geophys. Res. Lett., 31, L09301, doi:10.1029/2004GL019544, 2004.

McEwan, A. D.: The kinematics of stratified mixing through internal wavebreaking, J. Fluid Mech., 128, 47-57, 1983.

Marmorino, G. O., Rosenblum, L. J., and Trump, C. L.: Fine-scale temperature variability: the influence of near-inertial waves, J. Geophys. Res., 92, 13 049-13 062, 1987.

Mohn, C. and Beckmann, A.: The upper ocean circulation at Great Meteor Seamount, Part I: structure of density and flow fields, Ocean Dyn., 52, 179-193, 2002.

Moum, J. N., Hebert, D., Paulson, C. A., and Caldwell, D. R.: Turbulence and internal waves at the equator, Part I: statistics from towed thermistors and a microstructure profiler, J. Phys. Oceanogr., 22, 1330-1345, 1992.

Moum, J. N., Farmer, D. M., Smyth, W. D., Armi, L., and Vagle, S.: Structure and generation of turbulence at interfaces strained by internal solitary waves propagating shoreward over the continental shelf, J. Phys. Oceanogr., 33, 2093-2112, 2003. 
Orr, M. H. and Mignerey, P. C.: Nonlinear internal waves in the South China Sea: observation of the conversion of depression internal waves to elevation internal waves, J. Geophys. Res., 108, 3064, doi:10.1029/2001JC00163, 2003.

Pinkel, R., Sherman, J. Smith, J., and Anderson, S.: Strain: observations of the vertical gradient of isopycnal vertical displacement, J. Phys. Oceanogr., 21, 527-540, 1991.

Selschopp, J.: A towed CTD chain for high-resolution hydrography, Deep-Sea Res. I, 44, 147-165, 1997.

Thorpe, S. A.: Current and temperature variability on the continental slope, Phil. Trans. R. Soc. Lond., A 323, 471-517, 1987.

Thorpe, S. A. and Hall, A. J.: Evidence of Kelvin-Helmholtz billows in Loch Ness, Limnol. Oceanogr., 19, 973-976, 1974.
Turner, J. S.: Buoyancy Effects in Fluids, Cambridge University Press, Cambridge, 1973.

van Haren, H., Oakey, N., and Garrett, C.: Measurements of internal wave band eddy fluxes above a sloping bottom, J. Mar. Res., 52, 909-946, 1994.

van Haren, H., Groenewegen, R., Laan, M., and Koster, B.: A fast and accurate thermistor string, J. Atmos. Oceanic Technol., 18, 256-265, 2001.

Woods, J. D.: Wave-induced shear instability in the summer thermocline, J. Fluid Mech, 32, 791-800, 1968. 